\title{
W.F.R. Weldon Changes His Mind
}

\author{
Charles H. Pence
}

Received: date / Accepted: date

\begin{abstract}
A recent debate over the causal foundations of evolutionary theory pits those who believe that natural selection causally explains long-term, adaptive population change against those who do not. In this paper, I argue that this debate - far from being an invention of several articles in 2002 - dates from our very first engagements with evolution as a quantified, statistical science. Further, when we analyze that history, we see that a pivotal figure in the early use of statistical methodology in evolutionary theory, W.F.R. Weldon (18601906), changes his mind about precisely the central claim at issue. I close by drawing some morals which I think the case can offer for the contemporary debate going forward.
\end{abstract}

Keywords evolutionary theory $\cdot$ natural selection $\cdot$ causation $\cdot$ statistics $\cdot$ W.F.R. Weldon

\section{Introduction}

Consider a simplistic, cartoon presentation of evolution by natural selection. At the population level, we have fitness values for traits - somehow, at a minimum, indices of the traits' aptness for the environment or success at copying themselves into future generations, though the details are infamously difficult to work out (Ariew and Lewontin 2004; Sober 2013; Pence and Ramsey 2015) - which are taken to explain and/or predict (at least some subset of) changes in populations over time. Additionally, we can introduce an understanding of this change at the level of individual organisms. As is often discussed in the philosophy of biology literature (Mills and Beatty 1979; Brandon 1990; Pence and Ramsey 2013), particular individuals have propensities to survive and reproduce, and these are taken to explain and/or predict (at least some subset of) changes in the properties of the lineages of those individuals - with some lineages being more successful than others.

This is roughly the extent of current consensus, and it should be clear already that our picture leaves us with a dramatically underspecified interpretation of evolutionary theory as a whole. First and foremost, the individual and population levels are at minimum connected by a composition relationship - populations are made up of individuals. This means that

C.H. Pence

Institut supérieur de philosophie, place du Cardinal Mercier 14, bte. L3.06.01, 1348 Louvain-la-Neuve, Belgium

E-mail: charles@charlespence.net 
we should expect some account of further connections between the two levels of our story: between the individual propensities to survive and reproduce and trait fitnesses, between lineage structure change and population change, and between the explanations themselves offered at the individual level and those at the population level. Or, if those explanations are absent, we need an argument that tells us why. Lastly, we have yet to specify anything about how the proffered explanations at each level actually work. Are they causal, or no? If yes, which account of causal explanation is most perspicuous in this context?

Answers to all of these questions have tended to cluster into two groups. First, we have the "statisticalist" interpretation, a position inaugurated in the contemporary context by Walsh et al (2002) and Matthen and Ariew (2002). While there has been disagreement among these authors as to the details of the program, I will take the position of Walsh et al (2017) as definitive. On this view, precisely what makes natural selection interesting - in a manner analogous to statistical physics - is that explanations of population phenomena are insensitive to the details of individual phenomena. On the statisticalist picture, selection picks out a set of facts at the population level (namely, certain kinds of population arrangements, with certain kinds of growth rates, i.e., trait fitnesses, assigned to their parts), which, when they obtain, entail certain kinds of future population change as an analytic consequence. This thus offers us a specification of the connections between levels (or rather, an argument as to why we should ignore them), as well as a depiction of the kind of explanation at work at the higher level - a non-causal, analytic entailment of an interesting, statistical sort (and perhaps a unique one in the study of scientific explanation; see Matthen 2009; Ariew et al 2015).

The second cluster of answers seeks to preserve the causal nature of evolutionary explanations (with some even arguing that this is definitional of selection since the time of Darwin, e.g., Hodge 1987). Here, the diversity in positions is too large to offer a single definitive statement of the view, so I will have to be more schematic (and will cite only representative instances of the perspectives in play). Causalists first claim that one or both of the population- (Millstein 2006) or individual-level (Ramsey 2013) explanations offered by selection is in fact causal, whether via an approach that relies on a causal-process view of causal explanation (Millstein et al 2009), or by citing the supervenience of the populationlevel causal story on that at the individual level (Shapiro and Sober 2007). Further, causalist authors regularly search for connections between individual-level phenomena and those at the population level. One common tactic, for instance, is to define trait fitness as the average of individual fitnesses for all individuals bearing a given trait (though this is not uncontroversial; see Sober 2001). Similarly, one might search for connections between individual lineage change and long-term population change (Pence and Ramsey 2013). In all cases, though, these approaches are alike in that they wish to consider at least one of the selective explanations at issue causally, and they wish to ground such a discussion in a careful consideration of the relationship between populations and individuals.

While there are occasional references back to the history of biology - particularly in pursuit of a historical precursor such as Darwin (Hodge 1987) or Galton (Ariew et al 2017) - the debate is commonly thought to begin with the near-simultaneous publication of the two "founding" statisticalist papers I mentioned above, in 2002. In the nearly twenty years since, dozens of articles have followed, deepening the analysis of the controversy, staking out imaginative and interesting positions, but not, it seems, approaching anything like consensus.

It is my aim in this paper to offer two novel and interrelated perspectives on this discussion. First, I will pick up on a suggestion in my prior work (REDACTED 2015), which I failed to sufficiently flesh out there: namely, that this debate, far from being a product 
of the twenty-first century, is endemic to statistical approaches to selection - so much so that it in fact has been with us ever since the first attempts to develop such an approach to evolution in the 1880s and 1890s. A nuanced reading of the work of W.F.R. Weldon, one of the leading lights of the "biometrical" school (with Karl Pearson and Francis Galton), the first group of biologists to attempt to develop an entirely statistical understanding of natural selection, will show that he struggled with his position on exactly this problem. Beginning his career as a firm believer in the explanatory irrelevance of individual-level facts for population-level outcomes, Weldon ended it (with his untimely death) in the depths of the pursuit of connections between the individual-level details of heredity and inheritance and the population-level phenomena which they give rise to.

Second, and more provocatively, I want to offer a suggestion for a reading of Weldon's conversion that offers us a potential way forward in the prolonged and seemingly intractable debate over the causal structure of evolutionary theory. Weldon's turn, near the end of his life, to a discussion of the nature of statistical theorizing itself and the metaphysics of chance should offer an instructive lesson - it is high time for us to attempt to ground our approach to the theoretical structure of evolutionary theory in more general concerns.

\section{Weldon on Selection, 1893-1906}

W.F.R. Weldon (1860-1906), who went by Raphael, was a successful, young field biologist (specializing in invertebrate zoology) in 1889, when he read Francis Galton's new work, Natural Inheritance, the first book to marshal the young discipline of statistics (which Galton had drawn largely from Adolphe Quetelet) in the service of questions of the relationship between parents and offspring (Galton 1889). The course of Weldon's career was quickly changed. He prepared an initial paper offering a vast collection of measurements of shrimp and, when this article was eviscerated in peer review by none other than Galton himself (Weldon 1890a), worked directly with Galton to produce what would become his first contribution to statistical biology (Weldon 1890b).

Galton's approach to the role of statistics in biology was largely a static one (a feature which he inherited from Quetelet), with populations expressing normally distributed characters, and the lack of change in those normal distributions presenting a striking fact about the living world in need of explanation (to which Galton would add a rather confused picture of saltationist evolution in order to restore compatibility with Darwinism; Bowler 2014). Weldon, in inheriting that approach, was at this point entirely incapable of considering the impact of natural selection in statistical terms, even though understanding evolutionary change was one of the primary reasons that Weldon had adopted statistical theorizing in the first place. That would require a more sophisticated mathematical apparatus than Galton could provide. Luckily, Weldon took up a chair at University College, London, in 1890, which put him in contact with the mathematician and statistician Karl Pearson. Pearson's ability to construct the tools necessary to analyze non-normal distributions would provide just the leverage Weldon needed in order to think about evolutionary change.

\subsection{Early Weldon: The Crabs of 1893 and 1895}

The first results of this collaboration came in the two articles for which Weldon is now best known, both large-scale studies of small crabs found in two populations, one in the sound at Plymouth, near the Marine Biological Association where Weldon often performed field 


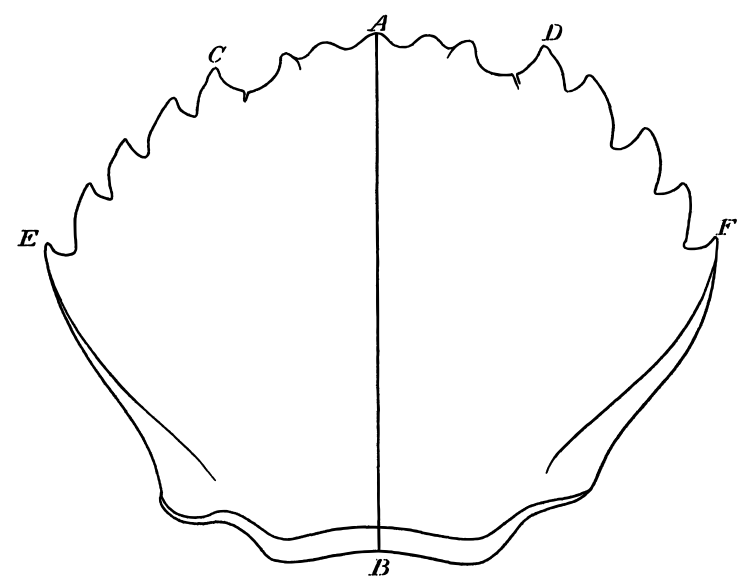

Fig. 1 Weldon's diagram of Carcinus manas, adapted from Weldon (1893). Frontal breadth (the asymmetrically distributed character of interest) is the distance here labeled C-D.

work, and one in Naples, at the Zoological Station (Weldon 1893, 1895). In the first paper, the data were fairly limited, and the conclusions that one could draw from them were limited in turn. Weldon took 1,000 measurements of a variety of morphological characters in these crabs, and found that every single one of them was normally distributed (consistent with Galton's view), save one measure in the Naples population - frontal breadth (see figure 1). This character showed a slightly non-normal distribution.

At first using his own sketch of curves by hand via trial-and-error, and later using a method expressly developed by Pearson for this purpose (Pearson 1895), Weldon factored that non-normal distribution into the sum of two normal curves. While he recognized that this hypothesis could not be fully supported by the data which he provided (in particular, without a much more detailed knowledge of the process of growth in the crabs, which I will discuss more below), Weldon cautiously proposes that these data could be the signal of natural selection dividing the population into two distinct sub-populations - the detection, that is, of incipient speciation in the wild. The 1895 paper is similarly cautious in presentation; its results appear to demonstrate the influence of stabilizing selection on the frontal breadths in the Plymouth species.

Neither paper, however, is cautious in its philosophical conclusions. Near the end of the first, Weldon writes that

before we can properly estimate the changes at present going on in a race or species we must know accurately $(a)$ the percentage of animals which exhibit a given amount of abnormality with regard to a particular character; $(b)$ the degree of abnormality of other organs which accompanies a given abnormality of one; $(c)$ the difference between the death rate per cent. in animals of different degrees of abnormality with respect to any organ; $(d)$ the abnormality of offspring in terms of the abnormality of parents, and vice versâ [sic]. (Weldon 1893, p. 329)

It's important, I think, to dwell for a moment on just how revolutionary such a pronouncement is. To modernize Weldon's language a bit, he argues here that in order to understand evolutionary change, we need to know the distribution of traits, the correlation between traits, the varying values of trait fitness, and the heritability of differences in traits - an ex- 
tremely modern picture of the foundations of evolutionary theory for 1893, and one that was entirely unprecedented.

Further, these data were not only necessary to understand the process of evolution but also, he thought, entirely sufficient, as he made clear at the end of the second paper:

These are all the data which are necessary, in order to determine the direction and rate of evolution; and they may be obtained without introducing any theory of the physiological function of the organs investigated. The advantage of eliminating from the problem of evolution ideas which must often, from the nature of the case, rest chiefly upon guess-work, need hardly be insisted upon. (Weldon 1895, p. 379)

Again, context is important. The kinds of traits that Weldon was studying - recall that his example here is a purely morphological character, of no obvious physiological function (about which more in the next subsection) - were relatable only with difficulty to straightforward effects on the organism's ability to survive and reproduce. But this is no hindrance. The advent of the statistical method makes such connections between population-level trait characteristics and properties of individual physiology simply unnecessary.

Early Weldon, then, as of the 1893 and 1895 papers, is a firm advocate of the view that the details of individual-level physiology and heredity are meaningless for the proper approach to natural selection, which should instead traffic only in population-level statistical variables. He therefore adopts the most significant core tenet of the statisticalist view, namely, the explanatory irrelevance of individual circumstances for statistically described population trends.

It is important to nuance this conclusion in two ways. First, Weldon remains a dyedin-the-wool field zoologist, and hence it would be too hasty to say that he has followed his own dictates consistently throughout his work. There is always an abiding concern with uncovering precise causal pathways in Weldon. But I don't think this gives us a reason to reject these extremely strident "programmatic" claims that appear in his most important papers from the early 1890 s.

Second, Weldon gives us no argument for why this should be so. To put it simply, the further implication that the explanation of population change in virtue of differences in character traits proceeds non-causally doesn't occur to him. In fact, it seems likely that he would have, upon reflection, rejected this consequence of the statisticalist picture for which he appears to be arguing above. When pushed directly on questions of causation by E. Ray Lankester (in an exchange to which we will return shortly), he begins (in a letter to Nature) by quoting the definition of causation from Hume's Inquiry, and continues by arguing that "when I have spoken of cause and effect, I have always endeavoured to use the words in accordance with the definition given in this passage or in Kant's extension of it" (Weldon 1896 b, p. 294). It is, of course, unclear to what extent Weldon's apprehension of causal inference should be trusted, and these passages, such as they are, were only produced under duress. Let's turn now to the circumstances of that duress.

\subsection{Middle Weldon: Debates of 1895-1896}

As Weldon's more provocative claims became better known, they began to attract polemical interest. In response to his 1895 paper (and, particularly, the very portion near the end of the paper that I cited above), E. Ray Lankester, the well known advocate of Darwinian gradualism who had taught Weldon at University College, wrote an incredulous letter. In his opinion, Weldon 
has deliberately departed from the simple statement which his observations warranted, viz. that such-and-such a proportion of frontal measurement accompanies survival, and has unwarrantably (that is to say unreasonably) proceeded to speak of the "effect" of this frontal proportion, to declare it to be a cause of survival to estimate the "advantage" and "disadvantage" of this same proportion, and finally to maintain that its "importance" may be estimated without troubling ourselves to inquire how it operates, or whether indeed it is operative at all. (Lankester 1896, p. 246, original emphasis)

The criticism clearly stung. For what Lankester did not know was that Weldon has, in the intervening time since collecting the data for the 1895 paper, become worried about precisely these sorts of questions, for a number of reasons.

First and foremost - and as Weldon had in fact clearly noted in the presentation of the data in both the 1893 and 1895 papers, though interestingly failed to note in the provocative philosophical conclusions of both papers - he knows that there are multiple ways in which a change in a character distribution might arise. "A diminution in the frequency of abnormal frontal breadth, with increasing size of crabs" (that is, the stabilizing selection around the mean which Weldon found in his 1895 Plymouth sample), he writes in a letter responding to Lankester, "might be due either to a selective destruction of abnormal crabs during growth, or to a modification of these crabs, by which abnormal individuals lose their abnormality as they grow" (Weldon 1896c, p. 413). That is, as I briefly mentioned above, without a clear knowledge of how these organisms change during the regular process of growth, we cannot know that any changes in the characters of the crabs that survive to maturity are the result of destruction by natural selection. Apparent selective bias in survival could simply be the effect of age-correlated change as the crabs grow.

"In order to decide which of these imaginative hypotheses should be adopted," Weldon continues, "I have spent a great part of the last two years in ascertaining the law of growth of crabs" (Weldon 1896c, p. 413), in a vast experiment involving raising crabs in jars at the laboratory at Plymouth. Such an experiment would, it seems, give knowledge of precisely the kind of physiological details about the development of crabs which Weldon had written, not one year before, were entirely unnecessary. Indeed, the contradiction is all the more acute. Near the end of the very same letter in which he describes his crab-growth experiments, he writes that

A complete knowledge of the processes associated with this relation between frontal breadth and death-rate is a thing of very great interest, ... [but i]t is not necessary in order that the change in mean frontal breadth may be measured from generation to generation, and the direction and rate of evolution by this means ascertained.

(Weldon 1896c, p. 413)

Which is it, we would like to ask: is an understanding of the physiological effects and growth characters of frontal breadths essential for understanding the evolutionary change in that character, or not? If experimental data are required, is it only the description of the crabs' growth that matters, or do we also need information about the physiological role of frontal breadths themselves? Weldon himself seems to be unclear on the matter, stuck in something of a transitional state.

One might argue here that Weldon's experiments in crabs are not genuinely on the hunt for causal influences. Given that he describes them as involving the "relation between frontal breadth and death-rate," perhaps he is simply performing a sort of observational study, designed to establish a statistical correlation while controlling for possible confounders? ${ }^{1}$ Such

\footnotetext{
1 I thank an anonymous reviewer for mentioning this potential objection.
} 
an interpretation is belied, however, by his experimental practice - in short, by the kind of work that he performs in order to approach the question that he lays out above, which would prove fruitful over the next few years.

\subsection{Late Weldon: Adaptation and Heredity from 1898-1906}

These experiments, in the two years after the flurry of correspondence with Lankester in Nature described above, provide Weldon with a mass of data significant enough to push him out of this transitional state. Both newly conceived experiments on the crabs at Plymouth Sound along with comparisons of Weldon's data on female crabs with a colleague's data on males, indicate that - even in the short period for which Weldon has been collecting data the frontal breadths have been detectably changing. Over just five years, the crabs have lost several percent in frontal breadth. Even without considering any hypothesis as to the nature or causes of such change, Weldon is surely right when he claims that "the frontal breadth of these crabs is diminishing year by year at a rate which is very rapid, compared with the rate at which animal evolution is commonly supposed to progress" (Weldon 1898, p. 898).

His occasion for making this observation was the Presidential Address of Section D (Zoology) of the British Association, which Weldon delivered on September 8, 1898, and which marked the first of two turns that would reshape Weldon's thought concerning natural selection - a dramatic leap in his belief that selection was a powerful force for adaptive change. For the change in frontal breadth is not merely idle. In the late 1890s, Plymouth Sound is in the process of silting up. The construction of a man-made breakwater prevents the fine clay which washes down from the rivers above from escaping to the sea, and hence it settles in the sound, mixed with the refuse of the massive shipping industry there.

Weldon thus tries another round of experiments to investigate the causal role of silt: "keeping crabs in water containing fine mud in suspension, in order to see whether a selective destruction occurred under these circumstances or not" (Weldon 1898, p. 899). And indeed, every such experiment demonstrates that crabs which survive in silty water have, on average, narrower frontal breadths than the crabs that die. He checks for a number of confounders, confirming on the contrary that (as best his data will allow), crabs kept in perfectly clean, silt-free water will tend to have significantly higher mean frontal breadths than wild-type crabs, and that the action of changes in frontal breadth appears to have something to do with filtration of the water prior to its reaching the gills. Indeed, the crabs which are killed, he finds, have their gills coated in a fine layer of silt.

These are not, then, merely experiments attempting to rule out certain kinds of confounders for a correlation between frontal breadth and later survival. Weldon has a specific hypothesis about the importance of a particular causal factor operating at the individual level - the silting of the harbor as a selective pressure - and he attempts to show directly how this factor leads to the kind of differential survival that would drive selection. Frontal breadth remains present in the explanation, but only as an intervening variable. The experiments are designed precisely to give the causal story for why change in that variable would be important in the first place.

For Weldon, this changes the tenor of natural selection itself, and shakes his former belief in the irrelevance of fine-scale details concerning individual characters for the determination of natural selection. It remains the case that "the whole of the difficulty of the theory of Natural Selection is a quantitative difficulty." But, and in contrast to his claims in 1893 and 1895 , he continues, 
it is the difficulty of believing that in any given case a small deviation from the mean character will be sufficiently useful or sufficiently harmful to matter. That is a difficulty that can only be got rid of by determining in a number of cases how much a given variation does matter; and I hope I have shown you that such determination is possible, and, if it be possible, it is our duty to make it. (Weldon 1898, p. 902)

He concludes by repeating a similar list of criteria for determining the impact of evolution as he had offered in 1895, but they now ring differently in light of his recent experimental work. When he writes that "we ought to know experimentally how much effect [a] variation has upon the death-rate" (Weldon 1898, p. 902), we can see that he now means that such experiments are to involve the painstaking collection of details of individual physiology and its impact on evolutionary success.

One important objection should be raised here. ${ }^{2}$ We might see Weldon's use of these crabs as nothing more than an expedient place to do some empirical research, capitalizing on a species available near his field site at Plymouth and amenable to the kind of analysis he was looking to perform at the time. On this view, there'd be no change of broader philosophical orientation indicated by this work, just an opportunistic study of a useful population. While something in this vicinity is undoubtedly part of Weldon's motivation, I think the combination of an increased emphasis on natural selection with the disappearance of the aggressive, statistics-focused language of Weldon's earlier work - both of which take place right around the shift to adaptation in the crabs - are too compelling in combination to discount a real change in Weldon's approach to evolution.

The second major shift in Weldon's thought is a result of the "rediscovery" of the work of Mendel, which Weldon first reads on October 16, 1900. Less than a month later, we see in correspondence that Weldon has, as a result, been gripped by worries about another individual-level influence: the structure of heritable material in individuals and the way in which it is passed to offspring. ${ }^{3}$ As he writes to Pearson,

I think that there must be an element in each gamete corresponding to every quality transmitted by it; some of these may blend with the corresponding elements of the other, some may exclude corresponding elements of the other, some may make a patch work resulting in a particulate [what we might call "variegated"] inheritance.

(Weldon 1900)

It is important to note, for readers like us living in a world after the work of R.A. Fisher and the modern synthesis, that this is not a disguised population inference. There is no infinite pool of gametes for Weldon, a feature of populations that would blend together and which is related to future individuals via a sampling process. ${ }^{4}$ To the extent that sampling is involved at all, it comes from the finite heritable resources of parents to produce the finite heritable resources of offspring. This is thus, for Weldon, very much a question of the properties of individual organisms and the ways in which those properties persist over time through their lineages.

This would become the central refrain of Weldon's response to Mendel, and to Mendel's defenders, such as Bateson, who endeavored to argue that Weldon's entire statistical ap-

\footnotetext{
2 Thanks to Gregory Radick for raising this objection.

3 It is worth noting that, while Weldon's focus on these questions was intensified in his response to Mendel's work, these are ideas that he developed during what I called the "period of transition" in the last subsection. Many of the basic ideas are present in a letter he writes to Galton in June, 1896 (Weldon 1896a).

4 For a nice reconstruction of these issues in Fisher's case, see Morrison (2002), though I am less certain that Morrison's claims about Pearson's lack of concern for biological detail would withstand scrutiny, and am certain that any such claims cannot justly be applied to Weldon.
} 


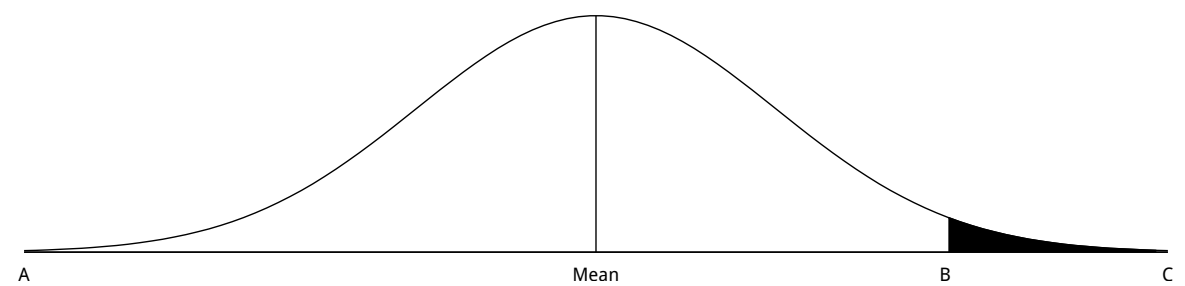

Fig. 2 Weldon's diagram of Mendelian "characters," taken from a letter to Pearson (redrawn after Weldon 1902).

proach could not be reconciled with Mendel's results. What we must do, Weldon claims, is find a relationship between the various properties of parental and offspring gametes that would successfully reproduce not only the generalized, statistical theory of inheritance for which Weldon had been advocating elsewhere, but also the laws of Mendel as a special case:

What Bateson does, and what all Mendelians do, is to take the diagram of frequency and to call a range $\mathrm{AB}$ one "character," and the range $\mathrm{BC}$ another "character" of a Mendelian pair.

\section{[figure 2]}

There must be a simple relation between $\mathrm{AB}, \mathrm{BC}$, and the S.D. [standard deviation] of the original system, which would make the chance that a grandchild falls within $\mathrm{BC}=\frac{1}{4}$ ? (Weldon 1902)

The Mendelians' failure to appreciate the full diversity of statistically distributed characters was their downfall. On the contrary, "the proper line of research is an inquiry into those embryonic stimuli which make a given character evident or latent. That is my fixed belief" (Weldon 1904).

This would be Weldon's primary line of research for the rest of his life. As he prepared for a series of public lectures that he gave at the end of 1904 and the beginning of $1905,{ }^{5}$ he began to turn more seriously to the question of the relationship between the underlying nature of the transmission of hereditary material and expressed phenotypes across multiple generations, attempting to derive a number of different laws for the transmission of character traits that he believed were found in the chromosomes.

As he put the point in a draft manuscript for a book based on those lectures, left unfinished at the time of his death, a purely Galtonian theory of inheritance - Galton had only attempted to gesture by vague analogy at the process of character transmission and the difference between characters that were expressed or merely latent - would not suffice. "The knowledge of cell-structure attained in 1872 [when Galton wrote out his mature theory of inheritance] did not make it possible to go beyond the suggestions indicated by such an analogy: we shall see in a future chapter how far the suggestion made can be brought into harmony with the facts of germinal structure which have been discovered during the last thirty years" (Weldon 1905c, ch. 2, f. 67r). Unfortunately, this "future chapter" of the manuscript was never written.

Thus, then, concludes Weldon's great shift: from a firm believer in the explanatory irrelevance of individual-level phenomena for evolutionary change, to a biologist fully en-

\footnotetext{
5 A series of anonymous accounts of the content of these lectures was published in The Lancet; see issues beginning with Weldon (1905a). (I follow common practice in citing them under Weldon's name as the lecturer; the author of the accounts is unknown, even to the journal's editors [pers. comm.].)
} 
gaged in both the search for physiological foundations for evolutionary changes, as well as for connections between the properties of individual parent- and offspring-gametes and the long-term dynamics of evolving populations. In short: from a statisticalist to a causalist. ${ }^{6}$

\subsection{Why the Change?}

It is dangerous to speculate about the motivations of historical actors. Weldon, in particular, left precious little documentary evidence. Much of what we know about the details of his research and his tribulations with Bateson and others comes as a result of Pearson's penchant for saving every scrap of correspondence which he ever received. But it would be equally irresponsible not to offer some possible reasons that Weldon could have made this move, at the time and in the way that he did.

First, we might point to a general phenomenon "in the air" in late-nineteenth and earlytwentieth century life science: an increasing preoccupation with the practical application of inheritance to breeding and horticulture. This concern - widely acknowledged by historians of science (Vicedo 1995; Hodge 2009) - was explicitly discussed by Weldon in a manuscript dating from 1905. He has begun to realize that, given his view of inheritance, "you cannot, by any amount of selection, reduce the original variability of a race beyond a certain definite amount" (Weldon 1905b, f. 24). If one's goal is to produce stable lines for agricultural purposes, this means that we have a task: "Accordingly, in every generation of" a population that we want to hold stable, "the variability has to be reduced, though the mean is no longer changed, by a selective destruction" (Weldon 1905b, f. 27). Understanding the nature of natural selection, in Weldon's new individualistic and inheritance-focused manner, can help us understand just how powerful that stabilizing selection needs to be.

Of course, this is late Weldon, well after the shift that I have identified in 1898. His view, as I have presented it here, of the importance of underlying causal detail to natural selection is indeed entailed by this approach to tackling the question of variation in agricultural productions - that is, one wouldn't think of the agricultural world in this way if one didn't have a causal approach to selection itself. But it's not implausible that Weldon's interest might have been drawn to questions in agricultural breeding and the production of stable types for independent reasons, and, recognizing this entailment, Weldon then had further reason to embrace a causal understanding of the process of natural selection.

There is one more possible motivation for Weldon's shift from statisticalism to causalism, but I want to return to it after pausing to consider a pair of objections which have, by now, surely occurred to a number of readers.

\subsection{Two Objections: On Whiggish History and Traits}

Surely, a motivated objector would have already noted, this is nothing more than the worst type of Whig history: the attempt to read into biologists of the late-nineteenth century a twenty-first century problem which they could not have understood, much less contributed to.

6 An anonymous reviewer notes that this makes for a significant difference between Weldon and his close colleague and collaborator Pearson, who had argued on the contrary that the concept of cause is meaningless and to be replaced by something like functional or statistical dependence (Pearson 1900). Indeed, the two men differed significantly in their conceptions of causation, a disagreement which appears clearly, among other places, in the correspondence pages of Nature, and which I have described elsewhere (REDACTED 2015 , under contract). 
One facet of the objection is certainly entirely correct. The philosophical sophistication surrounding questions of causal and non-causal explanations today is simply incommensurable with the state of such questions in the late-nineteenth century. Nothing like the clarity of the Salmon-Dowe account of causal processes, appealed to by Millstein (2013), or the custom-tailored account of statistically abstractive explanation deployed by Matthen (2009), could conceivably have been available to Weldon.

But to take this fact as a dismissal, tout court, of the applicability of Weldon's careful theorizing to the contemporary question of the causal structure of evolutionary theory is too quick. The question of the relationship between explanations at different levels of the biological hierarchy is not exactly an esoteric one - nor is it at all exclusive to evolutionary theory, as it arises in any context in which we have a "multi-level" theory with interconnecting relationships of causation and explanation. ${ }^{7}$

It is thus not at all surprising that the very first pioneers of statistical methodology in evolution would have had carefully worked-out positions on the question. Pearson was a respected author in what we would now gladly call philosophy of science; his Grammar of Science was eagerly read by a young Einstein, and the relationship of the philosophical picture he develops there with Mach's positivism is by now well known (Sloan 2000; Radick 2011; Pence 2011).

Rather than Whig history, then, I would argue that what we have here is instead a case of biologists quickly and readily seeing a central question in the interpretation of the kind of theory that they were in the process of developing, if today's philosophers of science will only pay attention to their thoughts on the matter.

A second objection might run something like this: Yes, you've successfully managed to detect a change in Weldon's position. But you're mistaken if you think that the final position of the late Weldon maps in any way onto that of the causalists - because, rather than the new lower level that Weldon alights upon being that of the individual, it's something more like traits or genotypes in a contemporary sense. So while there may be a version of a multilevel explanation problem here, it is not the classic one identified with the causalists and statisticalists, because it has one of the levels wrong. ${ }^{8}$

I've already given part of a reply to this objection above, but it bears repeating, because it's so foreign to anyone who has learned contemporary population genetics. It's important not to conflate Weldon's picture of inheritance with that which would arise in the wake of the modern synthesis. Weldon's view of the nature of heritable material (he never settled on a name for it, using terms like 'gemmules' or 'factors') is taken wholesale from Galton. They are physical characteristics of individual organisms, ${ }^{9}$ encompassing both "patent" characters (those actually expressed) and "latent" characters (those not actually expressed, taken to account for the phenomena of occasional reversion to characters borne by distant ancestors). The process by which the transmission of these characters occurred was as yet unknown to Weldon, as was the relationship between those characters and early cell biology (two failings which Weldon hoped to soon remedy); he could only argue that it was clear that their relative position within the organism was essential to the development of characters from them. But they remain a finite number of properties of individuals passed on to their offspring.

Put differently, we have here on the one hand nothing like a population characteristic - no gene pools, no indefinitely large numbers of gametes. We also have, on the other

\footnotetext{
7 While this is not the right context to explore the connection in detail, it is quite similar, for instance, to the question of "universality" in statistical physics; see Batterman (1998, 2000).

8 Thanks to Marshall Abrams for raising this objection.

9 For a delightful recounting of the debate between Galton and Maxwell over their physical nature, see Radick (2011)
} 
hand, nothing like a "genotypic" level. The emphasis for Weldon is always on the "embryonic stimuli" (as quoted above) that would lead to some particular character's developing (becoming patent) or not (remaining latent) in a particular, individual organism. The distribution of these characters and the statistical laws governing their transmission would remain a topic of research for Weldon in his last few years of life; Pearson would later publish a posthumously reconstructed version of these notes (Pearson 1908). In short, for Weldon, inherited factors set the scope of possibilities available to individual development; it would have made no sense for him to think about their inheritance except within the context of individual organisms and individual parent-offspring relationships. ${ }^{10}$

\section{From 1906 to 2021}

So much for the paper's first goal. If I have succeeded, you are hopefully convinced that Weldon was fully aware of the question in the interpretation of a newly statistical evolutionary theory that we have recently taken to calling the causalist/statisticalist debate. It is now time to pick up on the paper's second aim, and a thread I left open above: drawing from Weldon's second reason for changing from a statisticalist to a causalist picture some morals for how we might move forward on this debate in our own day.

In 1905, Weldon delivered a lecture at Oxford that would also serve as a contribution to a volume on the methodology of science (Weldon 1906). After having been one of the leading disciples of statistical methods in the life sciences for some twenty years, in this work he takes a step back and considers the reasons for which we might introduce chance and statistical methods into the life sciences in the first place. While the paper has much to offer (including Weldon's favorite demonstration of the nature of regression, involving a series of thousands of dice-throws tabulated by his wife Florence), for my purposes I want to zoom in on a contrast that he draws between the physical sciences and the life sciences, along with his concluding thoughts on the relationship between statistics and experiment.

Turning to another favorite example, he describes the experiments of Lord Rayleigh which led to the discovery of argon. Rayleigh, in measuring the densities of atmospheric gases, was persistently left with a remainder which he could not eliminate, despite the collection of further data and the utmost precision in measurement. Being certain, then, that the measurement represented a real phenomenon, if one that was as-yet inexplicable, he became convinced that there must be another gas at work - which would come to be isolated as argon.

Weldon astutely realizes that, appearances perhaps to the contrary, the step of genius here is not the inference to the presence of a new gas. Rather, it is Rayleigh's ability to be certain that, rather than experimental error, imprecise measuring equipment, or failure of the experimenter, the residual mass that he cannot account for is indeed a real physical phenomenon which cries out, at least in some way, for explanation.

Put differently, physical scientists, when they use statistical method, can use it as though it is a genuine law of error, quantifying the extent to which our (ever human) imprecise and imperfect measurements are approximations to some unknown, but still genuinely extant, real quantity which lies beyond them. Such was Quetelet's astronomically derived use of statistics that grounded his search for the "average man" (Quetelet 1835).

\footnotetext{
10 Morrison notes quite accurately that this is one reason that the mathematics of parent-offspring transmission remained intractable for the biometricians, and, by extension, one of the reasons that Pearson remained unable theoretically to separate genetic variation into its different sources, a feat that was much easier for Fisher (Morrison 2004, p. 1199).
} 
Biologists, however, have not been so lucky. As Weldon puts it,

[W]hile astronomers, chemists, and physicists have by great and successful efforts reduced the limits of uncertainty concerning the results of their observations until for many purposes they can neglect the discrepancies between the results of individual experiments, and treat their experience as uniform, biologists have not yet gone so far, and they are still forced to base such general statements as they can make on the characters of long series of observations. (Weldon 1906, p. 96)

How can biologists hope to catch up with their colleagues in the physical sciences? Perhaps the most important approach involves the elucidation of the laws that connect individual hereditary transmissions to broad population change. He offers us several exemplars of progress in this direction - alluding, as well, to his own work in the book manuscript we have already encountered. The first is what he calls "Weismann's theory of the mechanism, if I may use that word for want of a better, by which characters are transmitted from parent to offspring" (Weldon 1906, p. 99). Weismann's theory looks like a set of underlying causal laws that might ground one sort of statistical transmission, which Weldon introduces here by way of one of his experiments involving correlated tosses of red and white dice. The dice experiment is "still more closely analogous," he writes, "to the relation indicated as a result of direct statistical study of inheritance by Mr. Francis Galton" (Weldon 1906, p. 100) which, as we also have seen above, is essentially Weldon's own.

He closes the discussion of statistical methodology with, as he puts it, "a word to show you the kind of general statement to which work of this kind seems to lead" (Weldon 1906, p. 108). What we should hope for, in the end, is the guidance of statistics in showing us "how much we can predict about any group of unborn animals from a mere study of one parent." He continues: "By such a study, we learn some of the conditions on which the characters of the young depend: if we examine both parents, we learn more of these conditions; if we study not only the parents but the grandparents we learn still more; and so on" (Weldon 1906, p. 108). When asked to point out the most promising general sort of results to which statistical investigation of inheritance might lead, then, Weldon appeals to the utility of statistics in guiding our further experimental study of the character traits that are important for (selective, and other) biological explanations. "I can only hope," he concludes, "that I have helped you to realize a little of the difficulty which besets this form of experimental inquiry, and the way in which some part of this may be met and overcome" (Weldon 1906, p. 109).

Of course, this is not necessarily a research program that Weldon would himself have carried out. We have caught an empirical biologist at one of his most philosophical moments, and thus conclusions we draw here should be taken as "Weldonian" at best. His death, then, in 1906 at the age of 46 makes it impossible even to see what kind of empirical work he might have gone on to produce. But at the very least, Weldon seems to argue that we were due to rethink the fundamentals of the application of statistics to evolutionary theory. We can see him reaching, here, for a level of philosophical clarity that was broadly unavailable to him. The effort, I believe, still offers us a useful message about how we might move forward in today's causalist/statisticalist debate.

Weldon and Pearson had been locked for some twenty years in an unending effort to apply biological case studies in order to determine the theoretical structure of evolution by natural selection. Their correspondence is littered with data and diagrams, from shrimp to snails, poppies to Daphnia, basset hounds to racehorses. The contemporary literature has, in at least some quarters, followed suit (a different species of snails even reappears in Millstein 2008). 
Faced with the apparent intractability of the same problem in 1906, and pushed by the nature of the lecture series to which he was contributing to consider the problem more theoretically, Weldon took a step back, drawing links with other sciences (particularly the physical sciences), and attempted to generalize the problem to questions of the invocation of statistical method itself and the various possible structures that statistical theories might take - one would not, I think, be far off to term this an effort at the metaphysics of science. It is this Weldonian suggestion, I claim, that we should take seriously in the context of the contemporary debate. One response - and one so far not often taken in the philosophy of biology literature - would be to investigate ways in which both fruitful analogies with other sciences and fruitful connections with the metaphysics of science could allow us to build forward momentum on a problem that has been stalled (at least in the contemporary context) for nearly two decades (REDACTED in press).

\section{Conclusion}

Let's take stock. First, for the historical case. We have a number of biologists - here exemplified by the early Weldon, but also equally well demonstrated by parts of Fisher's work, ${ }^{11}$ among others - who are deeply invested in the irrelevance of individual-level facts for population-level explanations. Other biologists - here exemplified by the late Weldon, but also equally well demonstrated by Wright, ${ }^{12}$ among others - are deeply invested in the search for physiological grounding and interconnections between individual- and populationlevel evolutionary phenomena. To make the case for my first main claim, then, this question has been important to evolutionary theory from the very first days of "statisticalized" evolutionary science. ${ }^{13}$

To connect more clearly with the contemporary debate, let's return to a recent presentation of the statisticalist position which I briefly mentioned at the start of the paper, Walsh et al (2017). One of the defining characteristics of statisticalism, as its adherents argue there, is the substrate neutrality of models of natural selection. "The conditions for applying [a population-genetics model] may be realized in biological populations, but virtually nothing of what makes a biological population biological is explicitly represented in the model" (Walsh et al 2017, p. 11). On the contrary, these models only appeal to the statistical properties of the populations to which they are taken to apply. At first glance - echoing, I think, his early-career commitment to precisely this claim - we see a nearly identical argument advanced by Weldon. Again from his late, unfinished book manuscript:

A descriptive statement of the relation between the visible somatic characters of parents and those of children involves no biological hypothesis whatever, and requires no peculiarly biological methods for its compilation. When we compare the distribution of statures in two races of men... we have to compare two sets of objects

11 In one of his first papers now taken to establish the Modern Synthesis, Fisher writes that "if a complete analysis is unattainable it is also unnecessary to practical progress. [...] A number of points of general interest are shown to flow from purely statistical premises" (Fisher 1922, p. 415).

12 In response to Fisher on dominance, Wright focuses on the special cases required for Fisher's conclusions to go through, arguing that in the absence of them, rather than being supported by statistical principles, "probably most geneticists would hold that dominance in general has some immediate physiological explanation" (Wright 1929, p. 277).

13 It is also, interestingly, largely independent from the classic "debate between biometry and Mendelism" framing which has so dominated both historical and philosophical presentations of Pearson and Weldon. 
which differ in length; and the only thing we ought to consider while we are making the comparison is the number of inches... which each of these objects contains. (Weldon 1905c, ch. 1, f. 4r)

As classic an invocation of substrate neutrality as one could hope to find in a contemporary article: what counts here is the statistical distribution of characters, and "it does not matter in the least whether the objects measured are men" or something else entirely (Weldon 1905c, ch. 1 , f. 4r).

But we should not rest here - thus Weldon moves through the same narrative in his text that, I argue, he moved through in his thought more generally: "After we have made our comparison..., we ought to remember that we have been measuring men, and look for something in the phenomena of human development which may help us to see the process by which the observed relation between parental and filial stature has been brought about" (Weldon 1905c, ch. 1, f. 4r). As we saw in section 2.3, for the late, post-Mendel Weldon this will have much to do with the underlying nature of the determinants that give rise to these traits. For example, it is only by exploring the nature of those determinants that we will be able to distinguish between the possibility of Darwinian, gradualist natural selection and saltationist, non-Darwinian selection. Galton, as briefly noted above, had opted for saltationism, but Weldon noted that careful analysis of the role of these hereditary elements could settle the question either way:

If the determinant elements... are supposed to pass from one generation to another without any other variation except that involved in the assumption of the dominant or latent condition, then... the appearance of a new character must on such a view be ascribed to a process other than that of normal inheritance, leading to a "mutation" or "sport." If, however, the characters of each determinant may be assumed to vary to any extent, however slight, ... a gradual production of new characters... may conceivably result from a normal process of inheritance.... (Weldon 1905c, ch. 2, f. 66r)

No substrate-neutrality here, after all. In order to obtain such knowledge of the nature of natural selection, "we require to know the nature of the determinant elements themselves" (Weldon 1905c, ch. 2, f. 66r). A complete understanding of natural selection, for Weldon, requires a causal-experimental perspective on evolving systems in addition to a statistical one.

Given its venerable status in evolutionary theorizing, then, we can further note that despite more than a century's progress in both biological and philosophical theorizing, this issue persistently fails to be resolved. Some of the reasons that this failure might have been expected have been alluded to here. This is not simply a question of how to interpret a few isolated patches of biological data. For that matter, the question is not even exclusive to the biological sciences, recurring in any case in which a theoretical structure like that of evolution - multiple levels connected compositionally, but with explanations occurring on both levels ${ }^{14}$ - is found. How might we proceed?

The paper's second, and more schematic, thesis is that we might pick up on a suggestion which Weldon himself left us, and pursue in a systematic way both these connections with other sciences and generalized resources from the metaphysics of science. Very often, while certain kinds of surface-level analogies with statistical mechanics are, for instance, proposed

\footnotetext{
14 In addition to the analogy with physics mentioned above, I also lack both the space here and the expertise to pursue the similarity between this structure and that of the philosophy of mind; the only attempt, to my knowledge, to do so is Shapiro and Sober (2007).
} 
in the course of this debate, such analogies are not pursued in detail - for example, there is effectively no engagement to be found with the extensive literature in the philosophy of statistical physics - and hence such connections shed very little philosophical light on the problem at issue. When concerns in metaphysics are discussed at all, they are raised by implication or analogy rather than approached in general.

While I lack the space here to detail this project in full (see REDACTED in press for the complete case) a more engaged, dialectical connection with the literature in the metaphysics of science, whereby philosophers of biology take an active role in contributing to the analysis of the kinds of metaphysical questions about causation and multi-level explanation that could plausibly advance our understanding of this entire cluster of phenomena, would serve, I argue, as a way in which to take a true late-Weldonian approach to the philosophy of contemporary biology. Let's not let Weldon have changed his mind in vain.

Acknowledgements Prior versions of this paper benefited from comments from three reviewers. Thanks to audiences at EPSA 2019 in Geneva (especially Joe Dewhurst, Jan Potters, and Phyllis Illari), and at ISHPSSB 2019 in Oslo (especially Marshall Abrams, Greg Radick, Yafeng Shan, Mike Buttolph, and Stephen Hecht Orzack). Particular thanks, as always, to my partners in Weldoniana, Gregory Radick and Yafeng Shan, and to my guiding lights in post-Darwinian history of biology, Jon Hodge and Phil Sloan. This work was supported by the US National Science Foundation under HPS Scholars Award \#1826784.

\section{References}

Ariew A, Lewontin RC (2004) The confusions of fitness. British Journal for the Philosophy of Science 55(2):347-363

Ariew A, Rice C, Rohwer Y (2015) Autonomous-statistical explanations and natural selection. British Journal for the Philosophy of Science 66(3):635-658

Ariew A, Rohwer Y, Rice C (2017) Galton, reversion and the quincunx: The rise of statistical explanation. Studies in History and Philosophy of Biological and Biomedical Sciences 66:63-72

Batterman RW (1998) Why equilibrium statistical mechanics works: Universality and the renormalization group. Philosophy of Science 65(2):183-208

Batterman RW (2000) Multiple realizability and universality. British Journal for the Philosophy of Science 51(1):115-145

Bowler PJ (2014) Francis Galton's saltationism and the ambiguities of selection. Studies in History and Philosophy of Biological and Biomedical Sciences 48B:272-279

Brandon RN (1990) Adaptation and Environment. Princeton University Press, Princeton, NJ

Fisher RA (1922) Darwinian evolution by mutations. Eugenics Review 14:31-34

Galton F (1889) Natural Inheritance. Macmillan, London

Hodge MJS (1987) Natural selection as a causal, empirical, and probabilistic theory. In: Krüger L, Gigerenzer G, Morgan MS (eds) The Probabilistic Revolution, Volume 2: Ideas in the Sciences, Bradford Books, Cambridge, MA, pp 233-270

Hodge MJS (2009) Capitalist contexts for Darwinian theory: Land, finance, industry and empire. Journal of the History of Biology 42(3):399-416

Lankester ER (1896) Are specific characters useful? [letter of Jul. 16, 1896]. Nature 54(1394):245-246

Matthen M (2009) Drift and "statistically abstractive explanation". Philosophy of Science 76(4):464-487

Matthen M, Ariew A (2002) Two ways of thinking about fitness and natural selection. Journal of Philosophy 99(2):55-83

Mills SK, Beatty JH (1979) The propensity interpretation of fitness. Philosophy of Science 46(2):263-286

Millstein RL (2006) Natural selection as a population-level causal process. British Journal for the Philosophy of Science 57(4):627-653

Millstein RL (2008) Distinguishing drift and selection empirically: "The Great Snail Debate" of the 1950s. Journal of the History of Biology 41(2):339-367

Millstein RL (2013) Natural selection and causal productivity. In: Chao HK, Chen ST, Millstein RL (eds) Mechanism and Causality in Biology and Economics, Springer, New York, pp 147-163

Millstein RL, Skipper RA, Dietrich MR (2009) (Mis)interpreting mathematical models: Drift as a physical process. Philosophy and Theory in Biology 1:e002 
Morrison M (2002) Modelling populations: Pearson and Fisher on Mendelism and biometry. British Journal for the Philosophy of Science 53(1):39-68

Morrison M (2004) Population genetics and population thinking: Mathematics and the role of the individual. Philosophy of Science 71(5):1189-1200

Pearson K (1895) Contributions to the mathematical theory of evolution. II. Skew variation in homogeneous material. Philosophical Transactions of the Royal Society of London A 186:343-414

Pearson K (1900) The Grammar of Science, 2nd edn. Adam and Charles Black, London

Pearson K (1908) On a mathematical theory of determinantal inheritance, from suggestions and notes of the late W. F. R. Weldon. Biometrika 6(1):80-93

Pence CH (2011) "Describing our whole experience": The statistical philosophies of W. F. R. Weldon and Karl Pearson. Studies in History and Philosophy of Biological and Biomedical Sciences 42(4):475-485

Pence CH, Ramsey G (2013) A new foundation for the propensity interpretation of fitness. British Journal for the Philosophy of Science 64(4):851-881

Pence CH, Ramsey G (2015) Is organismic fitness at the basis of evolutionary theory? Philosophy of Science 82(5):1081-1091

Quetelet A (1835) Sur l'homme et le développement de ses facultés, ou Essai de physique sociale. Bachelier, Paris

Radick G (2011) Physics in the Galtonian sciences of heredity. Studies in History and Philosophy of Biological and Biomedical Sciences 42(2):129-138

Ramsey G (2013) Driftability. Synthese 190(17):3909-3928

Shapiro L, Sober E (2007) Epiphenomenalism - the dos and the don'ts. In: Wolters G, Machamer P (eds) Thinking about Causes: From Greek Philosophy to Modern Physics, University of Pittsburgh Press, Pittsburgh, PA, pp 235-264

Sloan PR (2000) Mach's phenomenalism and the British reception of Mendelism. Comptes Rendus de l'Académie des Sciences: Series III: Sciences de la Vie 323:1069-1079

Sober E (2001) The two faces of fitness. In: Singh RS (ed) Thinking about Evolution: Historical, Philosophical, and Political Perspectives, The MIT Press, Cambridge, MA, pp 309-321

Sober E (2013) Trait fitness is not a propensity, but fitness variation is. Studies in History and Philosophy of Biological and Biomedical Sciences 44(3):336-341

Vicedo M (1995) What is that thing called Mendelian genetics? Social Studies of Science 25(2):370-382

Walsh DM, Lewens T, Ariew A (2002) The trials of life: Natural selection and random drift. Philosophy of Science 69(3):429-446

Walsh DM, Ariew A, Matthen M (2017) Four pillars of statisticalism. Philosophy, Theory, and Practice in Biology 9:1

Weldon WFR (1890a) Letter from WFRW to FG, 1890-01-07

Weldon WFR (1890b) The variations occurring in certain decapod Crustacea. - I. Cragnon vulgaris. Proceedings of the Royal Society of London 47:445-453

Weldon WFR (1893) On certain correlated variations in Carcinus mœnas. Proceedings of the Royal Society of London 54:318-329

Weldon WFR (1895) An attempt to measure the death-rate due to the selective destruction of Carcinus mœnas with respect to a particular dimension. Proceedings of the Royal Society of London 57:360-379

Weldon WFR (1896a) Letter from WFRW to FG, 1896-06-06

Weldon WFR (1896b) The utility of specific characters [letter of Jul. 30, 1896]. Nature 54(1396):294-295

Weldon WFR (1896c) Utility of specific characters [letter of Sep. 3, 1896]. Nature 54(1401):413-413

Weldon WFR (1898) Address of the President of Section D (zoology). Report of the British Association for the Advancement of Science 68:887-902

Weldon WFR (1900) Letter from WFRW to KP, 1900-12-12

Weldon WFR (1902) Letter from WFRW to KP, 1902-06-23

Weldon WFR (1904) Letter from WFRW to KP, 1904-10

Weldon WFR (1905a) Current theories of the hereditary process [1]. The Lancet 165(4245):42

Weldon WFR (1905b) MS notes on animals and plants

Weldon WFR (1905c) MS of Theory of Inheritance book

Weldon WFR (1906) Inheritance in animals and plants. In: Strong TB (ed) Lectures on the Method of Science, Clarendon Press, Oxford, pp 81-109

Wright S (1929) Fisher's theory of dominance. American Naturalist 63(686):274-279 